\section{Microscopy Society of America Undergraduate Research Scholarship Program}

With this year's call for applications, the MSA Undergraduate Research Scholarship Program begins its 9 th year providing funding for undergraduate research. To date nearly 50 projects covering a wide range of topics in the physical and biological sciences have received support through this program. Abstracts, reporting the research results, are published annually in Microscopy and Microanalysis (formally JMSA) published jointly by the Microscopy Society of America and the Microbeam Analysis Society. Over the years nearly all of the scholarship recipients have maintained a strong interest in imaging sciences and have gone on to graduate school, professional school, teaching, or industry positions. The maximal award from MSA currently is $\$ 2,500$ and helps to provide student stipends, supply costs, and limited travel expenses associated with the research. Additional support in the form of instrument use time, equipment purchases, etc. is generally provided by the student's supervisor and/or through the sponsoring institution. The program is also actively seeking external sources of matching funds in order to maintain the favorable levels of support both in terms of the number of projects supported and the level of support for each.

The 1996 Awardees are as follows:

Erik Pauls: "Dental Microwear of Desmostylus and Paleoparadoxia" Junior, University of California Berkeley

Supervisor: Kent McDonald

Robb Pagarihgan: "Development of an Etching Protocol to Observe the Morphological Crystal Structure of Ultra High Weight Polyethylene in a Scanning Electron Microscope"

Junior, Palm Beach Atlantic College

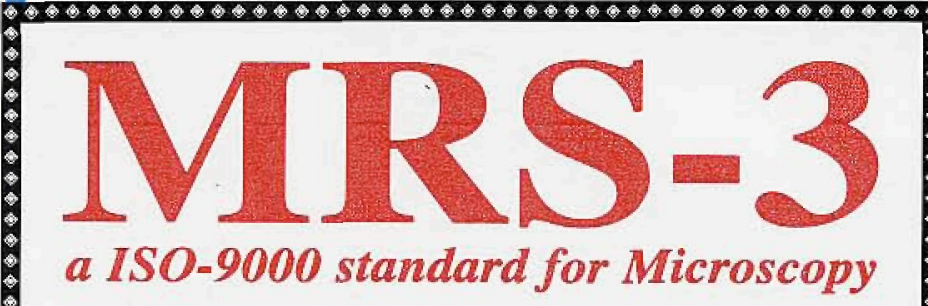

Our second generation, traceable, magnification reference standard for all types (SEM, Optical, STM, AFM, etc.) of microscopy. Usable from $10 \mathrm{X}$ to $50,000 \mathrm{X}$ with pitch patterns from $2 \mu \mathrm{m}$ $( \pm 0.1 \mu \mathrm{m})$ to $8 \mathrm{~mm}( \pm 0.25 \mu \mathrm{m})$. Pattern height traceable to $0.1 \mathrm{~mm}$ $\pm .001 \mu \mathrm{m}$. New patterns for parti-

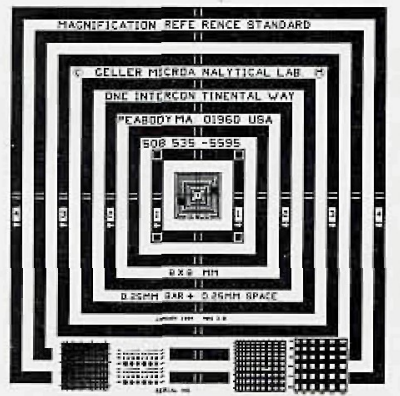
cle size counting (circles, squares and rectangles) and chemical imaging. Several hundred MRS's have been sold to date.

Send for our free RESOURCE GUIDE which discusses magnification measurement, error determination and calibration procedures.

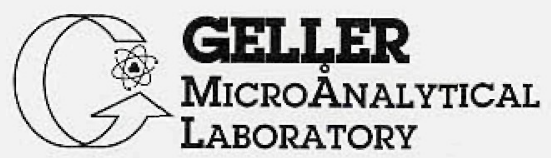

426e BOSTON STREET - TOPSFIELD, MA 01983 508/887-7000 - FAX: 508/887-6671 • geller@world.std.com
Supervisor: Melinda Harmon

Michael Davis: "Use of D-Limonene in Light and Electron Microscopy"

Senior, University of Texas at Arlington

Supervisor: Howard J. Arnott

Jean Gribbon: "The Effect of Prolactin on Cytoskeleton and Cell-Cell Junctions in Wounded Endothelial Cells"

Junior, The University of Arizona

Supervisor: Carrie Merkle

David Mahaffey: "Analytical Examination of NbxV1-x Cy N1-y Type Precipitates in an Experimental Forging Steel"

Junior, Illinois Institute of Technology

Supervisor: Robert Foley

Jennifer Gerlach: "Ultrastructural and Biochemical Analysis of Sphinganine Uptake and Metabolism in Neurospora Crassa"

Junior, Utica College/Hamilton College

Supervisors: Lawrence Aaronson/Kenneth Bart

The 1997 MSA Undergraduate Research Scholarship Program is currently soliciting applications from students interested in conducting a research project which involves the use of any microscopy technique. Students should be sponsored by a member of MSA. The application deadline is December 31 1996. Applications can be obtained from the MSA Business Office: (800)5383672 , or FAX: (508)563-1211.

If you have any questions or require additional information regarding the program please contact either:

Dr. Ralph Albrecht

University of Wisconsin

Dr. Richard Ornberg

(608)263-3952, Fax: (608)282-7420 (314)694-1184, Fax: (314)694-6727

\section{RESEARCH ELECTRON MICROSCOPIST}

The Materials Research Laboratory at the University of Illinois is seeking an experienced electron microscopist as a staff member in the Center for Microanalysis of Materials. The Center is a major research facility with eight electron microscopes as well as instruments in surface microanalysis, $\mathrm{x}$-ray diffraction, and other analytical techniques.

The person will work mainly on SEM, but should have the experience and flexibility to work also in TEM and possibly other techniques, if needed. The Center has two SEMs and a third may be acquired shortly. Experience in one or more of the following techniques would be especially important: Cathodoluminescence, EBSP, quantitative EDX. The main responsibilities of the position are to facilitate the research of the approximate 150 SEM users yearly, train new users, and keep the instruments running

There will be ample opportunity to carry out interactive research in the facility with the wide range of research programs. Possibilities for independent research could also be developed

This position requires a university degree in physics, materials science or a related field (Ph.D is desired) and at least three years experience with electron microscopes.

This is a 12 month, $100 \%$ time regular appointment with standard university benefits. Salary will be commensurate with education and experience. The position will be available in early 1997. In order to ensure full consideration, application must be received by November 30, 1996. Please send letter of application, resume, and names and addresses of three references to J.S. Eades, c/o Donna Jacobs, University of Illinois, Materials Research Laboratory, 104 South Goodwin Avenue, Urbana, Illinois 61801, phone (217)244-2944.

The University of Illinois is an Affirmative Action/Equal Opportunity Employer. 


\section{"BUT THEY SAID IT \\ WOULD WORK JUST AS \\ WELL AS A NANOSCOPE!"}

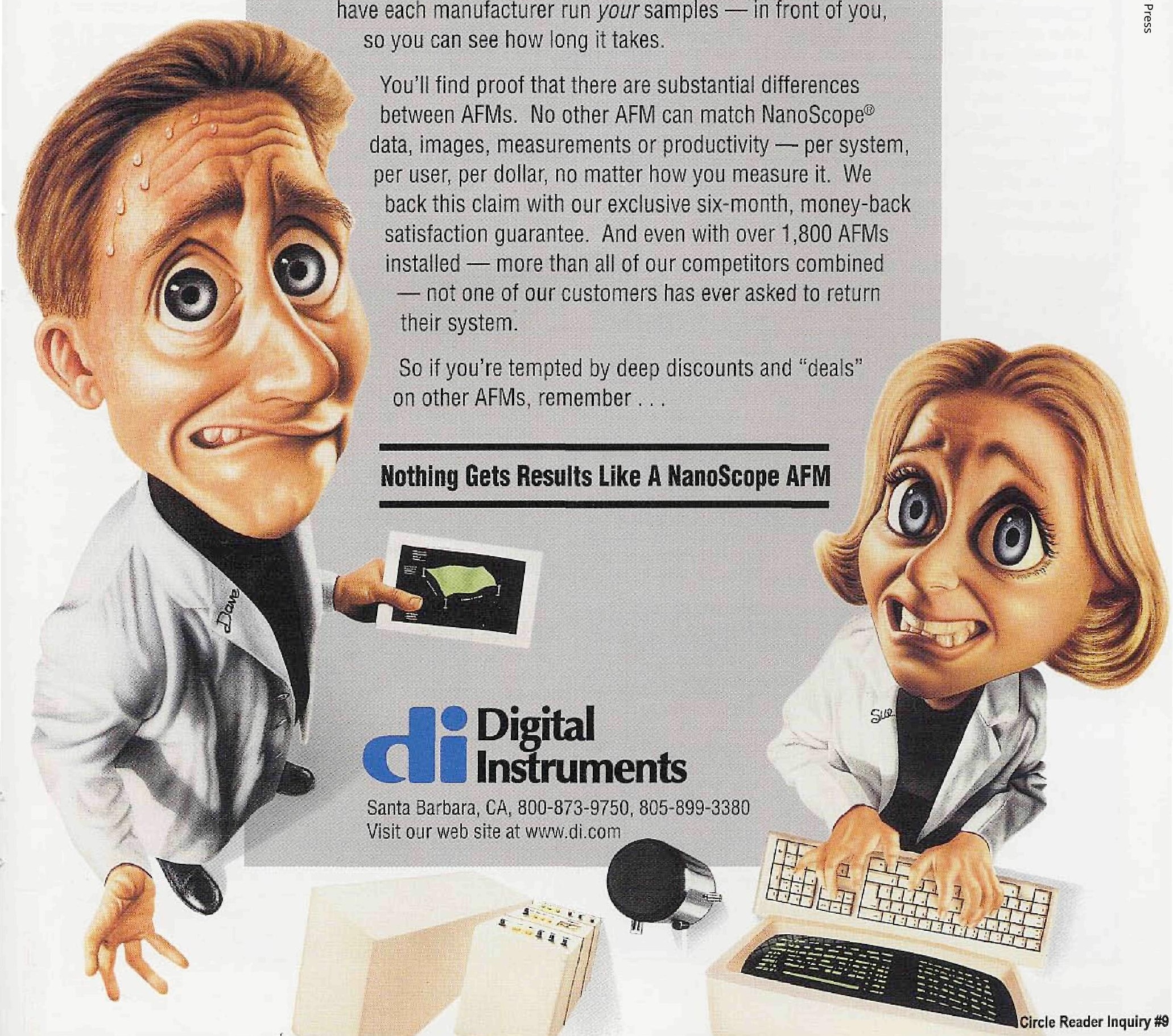

Qince buying an Atomic Force Microscope (AFM) is an important

$\checkmark$ investment in your future, we strongly recommend that you

carefully research your purchase: Talk to users in $R \& D, Q C$ or

process control. Check the scientific literature and go to confer-

ences. See whose AFM is generating the results. And, above all,

have each manufacturer run your samples - in front of you,

You'll find proof that there are substantial differences between AFMs. No other AFM can match NanoScope ${ }^{\oplus}$ data, images, measurements or productivity - per system, per user, per dollar, no matter how you measure it. We back this claim with our exclusive six-month, money-back satisfaction guarantee. And even with over 1,800 AFMs installed - more than all of our competitors combined

- not one of our customers has ever asked to return

So if you're tempted by deep discounts and "deals" on other AFMs, remember .. .

\section{Nothing Gets Results Like A NanoScope AFM}

Santa Barbara, CA, 800-873-9750, 805-899-3380 Visit our web site at www.di.com 